\title{
O cinema brasileiro e as identidades híbridas em Ruy Guerra: o olhar latino-africano de um cidadão da vida.
}

Anderson Lopes da Silva. ${ }^{1}$

Regiane Regina Ribeiro ${ }^{2}$

Falar do cinema de Ruy Guerra é falar de um conjunto de filmes que revelam reflexões sobre a identidade deste cineasta. Refletir sobre sua filmografia é uma atividade não muito fácil em decorrência de sua extensa produtividade, de alguns hermetismos presentes nela e, principalmente, pela qualidade de seu trabalho. Entretanto, é justamente este último aspecto que, paradoxalmente, também transforma esta atividade analítica - se não fácil, pelo menos - extremamente prazerosa. Por isso, poderíamos traduzir a obra deste diretor a partir de quatro adjetivos não limitadores: ela é perene, ousada, inovadora e autoral (Silva, 2013).

Um diretor que, em virtude de sua "vida nômade" pelo mundo e seu contato com as mais distintas expressões culturais, imprime seu olhar, sua peculiar maneira de ver o mundo e, a não menos importante, forma de relacionar-se com ele no conjunto de sua obra. Um olhar autoral sobre o ato de filmar, sobre seu ofício de cineasta.

Este artigo inicia-se, dessa forma, por mostrar o conjunto de obras do diretor e apontar laconicamente as temáticas e o estilo autoral presente nos filmes. Conseguinte a isso, a discussão direciona-se a falar da presença do cineasta no Cinema Novo no Brasil, realizando uma comparação entre as características estéticas do movimento, sua contextualização sociopolítica e cultural e, com mais destaque, o papel desempenhado

\footnotetext{
${ }^{1}$ Mestrando em Comunicação pela Universidade Federal do Paraná (PPGCOM/UFPR). Jornalista (FACNOPAR) e Especialista em Comunicação, Cultura e Arte (PUCPR). Membro do NEFICS (Núcleo de Estudos em Ficção Seriada) da UFPR. Bolsista Capes.

${ }^{2}$ Doutora e Mestra em Comunicação e Semiótica (PUC-SP). Docente permanente e pesquisadora do Programa de Pós-Graduação em Comunicação da Universidade Federal do Paraná (PPGCOM/UFPR)
}

Brasiliana - Journal for Brazilian Studies. Vol. 3, n.1 (Jul. 2014). ISSN 2245-4373. 
por Ruy Guerra enquanto um diretor que se sentia não muito incluso neste período (por muitos motivos), mas orgulhoso de ter deixado suas marcas nele.

Como aportes teóricos são usados as conceituações de hibridização cultural a partir da identidade de sujeitos diásporicos, e Guerra é um exemplo nítido, discutidas nos teóricos Homi Bhabha e Stuart Hall. Reflexões que versam sobre o caráter dos indivíduos que possuem uma visão sui generis acerca de si mesmo e da noção de pátria e nacionalidade.

Por fim, ainda acerca da identidade híbrida, a própria fala do cineasta é usada para ratificar o argumento principal deste trabalho: a ideia de que mesmo produzindo em terras tão diferentes do Brasil, ainda assim, o cineasta possui uma brasilidade estampada em suas obras, mas também uma versatilidade em saber lidar com suas multifacetadas identidades. Aliás, isto se torna uma característica tão marcante que ultrapassa a tela e chega ao seu modus operandi de fazer cinema.

\section{A cinematografia de Ruy Guerra e o Cinema Novo no Brasil}

“Sou tão Cinema Novo, tão pobre, que eu só sonho em preto-e-branco. Eu só sonhei uma vez a cores na minha vida, e é o sonho mais burro da minha vida". É assim que Ruy Alexandre Guerra Coelho Pereira se define ao falar de si mesmo e de sua paixão pela sétima arte.

Reconhecido como um dos maiores nomes do Cinema Novo brasileiro, Ruy Guerra nasceu no dia 22 de agosto de 1931 em Lourenço Marques, como a capital de Moçambique, atual Maputo, era conhecida até 1976. Filho de portugueses que viviam no país, então colônia da Coroa Portuguesa, Ruy Guerra desde cedo apresentava interesse por tudo que envolvesse o cinema. Prova disso é que, já em sua juventude, publicava 
críticas de cinema, alguns contos e resenhas, além de iniciar seus conhecimentos acerca da linguagem cinematográfica aprendendo a filmar com uma Super-8.

Luciana Mazzoti (2006, p. 9), ao tratar de sua biografia na obra "Ruy Guerra: filmar e viver", comenta que a velha câmera $8 \mathrm{~mm}$ dos tempos de "iniciante" ainda hoje pode ser vista na estante do diretor. Junto, segundo ela, dos dois Ursos de Prata recebidos em 1964 pela obra "Os fuzis" (1964) e em 1978 por “A queda" (1977), no Festival de Berlim.

Antes, porém, de sair de sua terra natal, Ruy Guerra foi um importante ativista dos movimentos anti-racismo e pró-independência de Moçambique. Até os dezenove anos de idade, o diretor foi uma figura importante dessas frentes que diziam muito sobre o seu posicionamento político e ideológico perante a crítica situação que seu país enfrentou durante anos, quando enfim chegou 1975, o ano da Independência.

Sobre a luta contra o racismo e o colonialismo português, Ruy Guerra em entrevista a Eduardo Portanova Barros, comenta que a figura de sua babá, a negra Rosa, foi fundamental para que ele criasse uma marca afetiva em seu imaginário com estas questões. “Nasci olhando aquela babá negra [...], a via tanto quanto minha mãe. Eu não podia aceitar a discriminação racial se tive uma mãe negra [...]". E finaliza: "Foi por causa dessa questão racial que eu comecei a tomar consciência da ditadura em seus aspectos políticos" (Barros, 2009, p. 262).

Entretanto até que se consolidassem as lutas da FRELIMO (Frente de Libertação de Moçambique), Guerra decide sair do continente africano e se autoexilar na Europa. Mazzoti explica que a passagem do diretor em Paris pelo IDHEC (Institute des Hautes Êtudes Cinemátographiques), de 1952 a 1954, foi de suma importância para o seu desenvolvimento artístico e intelectual. 
De acordo com a autora, seu trabalho final de curso na capital francesa, o curta "Quand le soleil dort" (1954), têm claras afirmações de seu criticismo ferrenho ao totalitarismo e às formas não democráticas de governo. O curta-metragem mostrava uma adaptação da edição em francês do romance italiano de Elio Vittorini ("Les hommes et les autres", de 1945), retratando um: "[...] campo de concentração de prisioneiros durante a II Guerra" (Mazzoti, 2006, p. 10). Foi neste mesmo instituto, como afirma Paulo Antônio Paranaguá (1997, p. 287), que ele travaria contato com o colega e futuro co-autor do primeiro roteiro de "Os fuzis" (1964), o francês Pierre Pelegri.

A partir daí, Ruy Guerra faz cursos complementares em televisão e teatro, durante o período pré-Nouvelle Vague na França, e começa a exercitar muitas funções na dramaturgia como assistente de câmera, fotógrafo de documentários, assistente de diretores como Jean Delannoy e Patrice Dally, além de iniciar na direção cinematográfica como estagiário e ator do longa-metragem "S.O.S Noronha" (1956) de Georges Rouquier.

Como ator, participou ainda de filmes de Serge Roullet, Jean Daniel Pollet, Pierre Kast e Werner Herzog durante os anos 1960 e 1970 na Europa. No mesmo período, após receber o convite da atriz Vanja Orico para dirigir um filme no Brasil, Ruy Guerra vem ao país e acaba radicando-se brasileiro aos 27 anos. $\mathrm{O}$ filme que nunca foi realizado (com o prévio nome de "Joana Maluca" e um argumento sobre a lenda do boto), pelo menos foi o responsável por trazer o diretor que, nos próximos quatro anos, realizaria uma de suas maiores obras: o filme "Os cafajestes" (1962).

Sobre a chegada de Guerra ao Brasil, antes ainda de "Os cafajestes", Glauber Rocha pontua que sua primeira impressão daquele homem "sem barba que viera de Paris", não foi das melhores. A explicação de Glauber é curiosa por tratar de uma cena de "O cavalo de Oxumaré" (1960), um filme inacabado de Ruy Guerra e Miguel Torres, 
no qual a atriz Irma Alvarez tem a cabeça raspada por Guerra. Glauber Rocha viu aquilo como uma espécie de afronta, um plágio, já que ele também preparava "Barravento" (1962) no mesmo período com cenas que também tratavam do candomblé na Bahia.

O diretor brasileiro revela que no calor do momento chegou a pedir: “[...] a expulsão do alienado franco-moçambicano luso-colonialista." Porém, depois de um tempo, explica: "Nem por isso ficamos inimigo" (Rocha, 2006, p. 39). E foi durante o cinema novo no Brasil que estes dois cineastas se aproximaram mais ainda. Tal período representa um marco não apenas para a história da cinematografia nacional; mas também é visto por críticos e acadêmicos como um movimento artístico que deixou um grande legado à história mundial do cinema.

Isso se deve às suas características estéticas, ousadia e de inovação que o referenciam quando se discute a linguagem cinematográfica e a temática político-realista da sociedade brasileira dos anos 1960. É sabido também da importância histórica e cultural de outros dois grandes movimentos cinematográficos internacionais, muito próximos ao período do cinema novo brasileiro. Trata-se do Neorrealismo italiano e da Nouvelle vague francesa; fortes influenciadores desse período.

Seguindo conceitos advindos de tais obras e diretores como Rossellini, De Sicca, Truffaut, Godard, entre outros, os brasileiros Glauber Rocha, Nelson Pereira dos Santos, Ruy Guerra, Anselmo Duarte, Cacá Diegues, Roberto Farias, Trigueirinho Neto e outros nomes importantes, produziram em terras brasileiras produções, como já ditas, de relevância internacional.

Marcos Graça (1997, p. 25), utilizando-se das explicações de Ismail Xavier, muito objetivo, mas não simplista, define o período como o fruto da importante "atividade e revolta de um grupo de jovens intelectuais burgueses de esquerda, insatisfeitos com a nossa realidade social e dependência cultural das linguagens importadas", ou seja, um 
grupo que não se via e nem conseguia enxergar o Brasil no onipresente "padrão de cinema de Hollywood".

O CPC (Centros Populares de Cultura), outro grupo formado também por cineastas e estudantes (já que sua origem remete à UNE - União Nacional dos Estudantes ), rivalizava com os diretores do Cinema Novo, mas tinha uma visão parecida no que diz respeito à conscientização política das "massas" por meio de um cinema crítico e à parte do comercial.

Entretanto, o CPC entrava em choque com os cinemanovistas quando o assunto era "a forma" de se construir um cinema, uma arte e uma estética em prol do político e do social. Os diretores e membros do CPC produziam obras (como "Cinco vezes favela", "Zé da Cachorra" e "Escola de Samba Alegria de Viver") que tratavam do popular e pretendiam democratizar o acesso às comunidades mais pobres ofertando, por meio do cinema, a educação e a cultura; todavia, de um modo bem simples, sem muita ousadia ou experimentalismo na arte cinematográfica.

Pensamento oposto tinham os cinemanovistas que viam nesta atitude uma demagogia e um autoritarismo disfarçados que criavam um novo tipo de censura: a censura à liberdade criativa e autoral (o que levou diretores como Cacá Diegues e Leon Hirszman a sair do seio "cepecista" e se instalar em meio aos diretores-autores do Cinema Novo). Ser simples em demasia reduzia a capacidade questionadora do cinema, diziam os representantes do movimento.

Graça divide o período do Cinema Novo em três fases temáticas que abarcam as obras ficcionais do período, levando em consideração algumas exceções, e que podem ser descritas da seguinte forma: 
[...] a que trata das questões do nacional e do popular no ambiente rural de 1962 a 1964: a que trata do começo da discussão do urbano e os efeitos do golpe de 64, em conjunto com as preocupações da primeira fase, em 1965 e 1966 e a autocrítica visceral em 1967 e início de 1968 (1997, p. 26).

Estas produções denotavam não pertencer simplesmente a mais uma experimentação cinematográfica limitada às fronteiras do país. Para tal ideal, levar o cinema brasileiro para fora, de acordo com Saraceni, era necessário aproveitar a presença do escritor e embaixador brasileiro Paulo Carneiro (que estava na Unesco), o crítico Almeida Salles como adido cultural em Paris e o renomado diretor e produtor italiano Gianni Amico, que ele chama de "guru" do movimento. "Ninguém melhor que ele para introduzir esse cinema novo recém-nascido" (Saraceni, 1993, p. 111).

Assim, durante a década de 1960, o Cinema Novo do Brasil começou a se desenvolver de maneira muito ligada aos conceitos ideológicos de então, como o período pós-guerra e a forte conotação do binômio nacionalismo-modernidade que vigora na época. Paulo Emílio Sales Gomes (1966, p. 81) não deixa de destacar que: “Os cinco primeiros anos da década de 1960 são dominados [...] pelo fenômeno baiano, que se constitui de um conjunto de filmes produzidos na Bahia, produzidos por baianos e outros por sulistas [...]". O crítico de cinema brasileiro comenta, ainda citando a projeção de Glauber e de seu "poderoso Deus e o diabo na terra do sol", que foi justamente neste período que o cinema moderno brasileiro viu suas maiores produções em matérias de ficção e documentário, sendo este movimento, segundo o autor, a terceira maior revolução artística no país depois da Bela Época e da Chanchada. 


\section{Ruy Guerra: um cineasta do Cinema Novo?}

É justamente no Cinema Novo que Ruy Guerra realmente destaca-se nacional e internacionalmente. Sua presença nessa fase do cinema brasileiro fez com que suas obras (em especial "Os fuzis" e “Os cafajestes”) figurassem na tríade do Cinema Novo, ao lado de Glauber Rocha (com “Deus e o diabo na terra do sol", em 1964) e Nelson Pereira dos Santos (com “Vidas secas", em 1963).

Glauber Rocha, mesmo criticando seu "meio-irmão", como ele se refere ao diretor, confirma que neste período Ruy Guerra surgiu na imprensa como o diretorautor de maior expressividade do Cinema Novo que acabava de emergir no país:

A Nouvelle Vague estava na ordem do dia, Truffaut passava no Rio na Semana de Lançamento de Os Cafajestes, o país inteiro tomou conhecimento do escândalo visual proibido e retirado de cartaz no auge do sucesso, por ordem de Carlos Lacerda, então governador do Estado da Guanabara. Em Belo Horizonte, a TFM fez passeata contra Norma Bengell que aparecia nua envolvida por um travelling de quatro minutos. [...]. Quando Ruy quis alegar os motivos políticos dos censores, lhe responderam que o filme fora proibido por questões morais (Rocha, 2006, p. 39).

Não bastasse a passeata da Tradicional Família Mineira contra o primeiro nu frontal do cinema brasileiro, as desavenças internas de produção, fizeram com que Ruy Guerra e Jece Valadão, ator e produtor executivo do filme, discutissem seriamente os conceitos do 
diretor que "vomitava bossas" trazidas do IDHEC para Copacabana e Cabo Frio, como conta Glauber Rocha (2006, p. 39).

Sobre o sentimento de "pertencimento" ao grupo dos cinemanovistas, Ruy Guerra, em entrevista ao jornalista Inimá Simões, do programa Sintonia, diz que até hoje não sabe muito ao certo qual foi o sentido de sua presença dentro deste período. Mesmo tendo ativa participação e contato "num convívio diário" com diretores como Leon Hirzsman, Joaquim Pedro de Andrade, Cacá Diegues e Nelson Pereira, ainda assim, Ruy afirma, em seu tradicional tom contraditório (sem que aqui o adjetivo tenha um viés pejorativo) que:

Eu era um pouco um corpo estranho. [...] Nunca fui um homem de grupo, nunca tive essa vocação. Sou muito solidário, mas sou muito "louco solitário" por outro lado. [...] E porque tenho essa coisa um pouco arredia, eu também me auto-marginalizei. Eu ficava integrado e ao mesmo tempo me auto-marginalizava dentro disso. Mas me considero um cineasta do Cinema Novo, sim. E com muito prazer e orgulho do que o Cinema Novo fez (Guerra/TV Câmara, 2009).

Dois anos depois da polêmica e do estrondoso sucesso de "Os cafajestes", Ruy Guerra lança "Os fuzis" e se aproxima ainda mais da temática do nordeste e das mazelas sociais tratadas por outros diretores do período. E, como de costume, mais uma vez enfrenta problemas de ordem política e, principalmente, de ordem produtiva.

Ricardo Aronovich (2006, p. 37), diretor de fotografia, fala de um desses problemas quando de sua participação em "Os fuzis". Segundo ele, nos momentos das 
filmagens, por exemplo, as condições de hospedagem eram muito primitivas, contudo: “[...] a vontade de trabalhar com alguém que realmente entendia de cinema, [...] não tinha preço".

Além disso, o segundo longa-metragem de Guerra, de acordo com o diretor de fotografia, tinha outra especificidade que fazia da obra algo totalmente inovador no cenário cinemanovista: o método de trabalho com os atores e os singulares ensaios onde a atuação era feita quase de improviso, com diálogos feitos sob o sentimento dos próprios atores. Era o que se chamava nesse momento de "laboratório" (Aronovich, 2006, p. 38). Juntos, os dois profissionais ainda trabalhariam na França na produção de "Sweet Hunter" (1969), filme tido como cult na Europa e que nunca foi exibido comercialmente ou em festivais no Brasil.

Depois desse período, Ruy Guerra volta a Moçambique (agora não mais colônia de Portugal) e filma os curtas-metragens "Operação Búfalo" (1978), “Um povo nunca morre" (1980), "Os comprometidos - actas de um processo de descolonização" (1984) e o longa-metragem "Mueda - memória e massacre" (1979). De volta ao Brasil, faz participações na história da Música Popular Brasileira como letrista (com Sérgio Ricardo, Edu Lobo, Nara Leão, Milton Santos, entre outros) e, no auge da censura ditatorial brasileira, escreve para o teatro "Calabar, o elogio da traição", juntamente com Chico Buarque (parceiro também na música). Ruy Guerra ainda passou, neste período, pela TV e pela direção de espetáculos e shows musicais.

Com igual ou maior destaque, sua parceria com o consagrado escritor colombiano Gabriel García Márquez (o Gabo) lhe rendeu os filmes "Erendira" (1982) e "A fábula da bela Palomera" (1987). A série filmada na Espanha e Portugal, mas produzida em Cuba (em mais um momento de seus autoexílios), "Me alquillo para 
soñar" (1991/1992) e seu mais recente filme "O veneno da madrugada" (2004/2005), são mostras de que as produções conjuntas tiveram força e resistência ao tempo.

Luciana Mazzoti (2006, p. 12) cita que García Márquez, em um de seus livros, comenta que a relação se firmou na franqueza com que ambos tratavam o trabalho de roteiro e direção. "O diretor com quem melhor trabalho é Ruy Guerra", sentencia Márquez. Nos anos 2000, Ruy Guerra realizou obras tanto no Brasil ("Estorvo" em 2000) quanto em Portugal (“Monsanto", também em 2000, e “Portugal S.A.", em 2003).

Deste período até agora, nos três projetos de longa-metragem que planeja aos 82 anos de idade, pode-se dizer que muitas coisas tenham mudado no mundo, nos países por onde ele passou e na própria vida do diretor. Contudo, sua visão quanto aos princípios da linguagem do cinema parece não se alterar. Sólido o bastante em meio à tantas mudanças, ele diz: "Acho que toda estética é política, e eu procuro uma estética que esteja vinculada às minhas concepções política e ideológicas" (Guerra, 2006, p. 26). Isso se reflete nos 14 longas-metragens, 12 curtas, nas aulas e cursos universitários de linguagem cinematográfica fundados por ele, nas (não muito conhecidas, mas belas) crônicas no jornal O Estado de S. Paulo, poesias e outros escritos, nas peças de teatro, nas parcerias musicais como letrista e nas inúmeras outras funções que Ruy Guerra vem exercendo anos a fio no cenário cinematográfico.

\section{A representação das identidades híbridas a partir da linguagem}

Tal qual Stuart Hall, o crítico indiano Homi Bhabha escreve, pensa e vive as problemáticas suscitadas pelo pós-colonialismo, neste caso, tendo a Inglaterra (colonizadora) e a Índia (colonizada) como o pano de fundo de suas discussões. Suas ideias e conceitos acerca da hibridização surgem num contexto de confronto na 
literatura de ex-colonizados e ex-colonizadores; um embate entre qual das formas de representação literária representariam mais ou menos fidedignamente a realidade dos nativos.

A preocupação com os processos híbridos surge a partir de sua experiência própria como membro de uma elite local (os Parsi, de Mumbai) presente numa sociedade colonizada pelos ingleses durante dois séculos. De igual modo, tais discussões iniciam-se também a partir do objeto de análise de seus trabalhos iniciais, isto é, o discurso colonial britânico na Índia do século XIX.

Criticando a análise de imagens e a análise ideológica dos textos, Bhabha não traz a mesma abordagem "realista" da literatura e das suas representações identitárias da cultura e da hibridização. Para ele, ao passo que a análise de imagens era demasiadamente simplista por acreditar na neutralidade dos sujeitos e ignorante dos aspectos históricos e sociais que circundam os autores e leitores destas mensagens; a análise ideológica, por sua vez, também peca pelo excesso de distanciamento entre o sujeito e o objeto analisado, tentando evitar ao máximo (e por isso mesmo esquecendose) dos aspectos ligados à subjetividade do analista e postulando uma transcendência do discurso. Assim, utilizando-se da desconstrução de Derrida, a crítica de Bhabha está voltada principalmente à representação violenta que separa sujeito e objeto, fixando, sempre, o sujeito numa posição de inteligibilidade hierarquicamente privilegiada (Souza, 2004).

A partir desta recusa metodológica em analisar a cultura e seus produtos de modos enviesados, a ótica sob a qual o pesquisador percebe os processos de hibridização passa a ser àquela que busca sempre não definir a realidade dos sujeitos, mas sim a própria definição do que se entende por este sujeito colonizado e póscolonizado. Em outras palavras, de acordo com Souza (2004), é pelo caminho da 
linguagem que Homi Bhabha busca a identidade, ou seja, é no nível do discurso que ele traça sua rota com o intuito de compreender as traduções culturais e a hibridização que as constituem. “O enfoque de Bhabha, no entanto, era de entender o que estava realmente em jogo nesse confronto: se eram as linguagens usadas para representar os sujeitos ou [...] a questão da construção da identidade", afirma Souza (2004, p.114).

A busca pela identidade, de acordo com Homi Bhabha, é sempre agonística porque a identidade é sempre uma imagem, e ainda que "muito autêntica", ela continua sendo imagem (e, por isso, nunca é substancial). Bhabha explica que o acesso à imagem da identidade só é possível por meio de uma negação do sentido de originalidade ou da ideia de plenitude, "através do princípio de deslocamento e diferenciação (ausência/presença; representação/repetição)" que de uma forma ou de outra torna a realidade ambígua. E, nestes termos, o processo relacional da identidade (a imagem) é de modo dúbio uma "substituição metafórica, uma ilusão de presença" e, por isso mesmo, uma "fronteira movediça da alteridade na identidade" (Bhabha, 2010).

Neste sentido a reflexão acerca da identidade híbrida de Ruy Guerra encaixa-se perfeitamente na leitura proposta por Bhabha. Guerra vivenciou todos estes processos agonísticos de uma "não identidade nacional fixa ou monolítica". Ao falar sobre sua vida como um moçambicano branco que nasce num colônia portuguesa e, já a partir daí, não é nem mesmo um "natural" moçambicano, mas sim "um português de segunda classe" (como todos aqueles advindos das colônias), é possível perceber o quão complexo é o jogo das identidades nessa configuração. A imagem (ou melhor, a autoimagem) de sua identidade não é nada nítida: ela é dúbia.

A ideia de uma fronteira movediça da alteridade na identidade é outra concepção que se aplica à leitura ensejada no artigo. O cineasta transparece tal "sentimento volúvel de identidade" a partir de um olhar que não se fixa numa pátria ou ideia de nação 
enquanto porto único de ancoragem do sujeito. Guerra permite-se trabalhar nessa fronteira entre aquilo que é o Brasil conhecido por ele, entre Portugal como a terra de seus pais e o Moçambique pelo qual lutou pela liberdade.

Essa possível contradição entre a definição de “Quem sou eu afinal?" do ponto de vista identitário, não parece preocupar nem um pouco Ruy Guerra. Pelo contrário: é através desse jogo de identidades que caminha por entre as tramas da hibridização cultural que sua obra é realizada. É por meio desse caminho não tão claro sobre a sua ideia de identidade que suas produções audiovisuais são pensadas, filmadas, exibidas e refratadas no olhar de um cineasta tão híbrido quanto sua história.

Assim, quaisquer das tentativas de representação identitária tornam-se multifacetadas por conterem traços dos dois discursos, dos discursos que se misturam num complexo jogo de alteridade e distinção, no qual intentar uma autenticidade é algo impossível. Numa definição que antecipa suas discussões acerca do entendimento de uma "tradução cultural" dos processos hibridizadores, o crítico indiano afirma:

“A hibridização não é algo que apenas existe por aí, não é algo a ser encontrado num objeto ou em alguma identidade mítica 'híbrida' - trata-se de um modo de conhecimento, um processo para entender ou perceber o movimento de trânsito ou de transição ambíguo e tenso que necessariamente acompanha qualquer tipo de transformação social sem a promessa de clausura celebratória, sem a transcendência das condições complexas, conflitantes, que acompanham o ato de tradução cultural" (Bhabha, 2002 apud Souza, 2004, p. 113) 
Dessa forma, pensar a hibridização em Bhabha é partir do conceito de discurso como uma prática significatória. Em outras palavras, na esfera linguística a identidade e a sua representação estão umbilicalmente presentes num "processo que postula a significação como uma produção sistêmica situada dentro de determinados sistemas e instituições de representação - ideológicos, históricos, estéticos, políticos" (Bhabha, 1984, p. 98).

É neste lócus de enunciação que se encontra o entendimento da "tradução cultural" de Bhabha. É neste espaço social e político e dois quais múltiplos atores participam, que o processo de justaposição e adaptação de culturas entra em choque. Neste sentido, a rede de significações é colocada em ação por meio de "traduções" que promovem releituras da diferença. E assim como afirma García Canclini (2011), para Bhabha as traduções culturais são estratégias de sobrevivência em meio ao embate desta diferença. Uma estratégia que é ao mesmo tempo tradutória, mas também transnacional, já que, no contexto das colonizações, ela é marcada por experiências e vivências de ordens apenas conhecidas pelo deslocamento dos locais de origem (Souza, 2004).

Sem cair na tentação de criar um perigoso relativismo cultural, Bhabha ressalta que a hibridização faz parte desta tradução cultural, pois promove um deslocamento também das significações linguísticas e não apenas o deslocamento literal das imigrações. Comentando sobre o assunto, ele afirma que a tradução é também uma maneira de imitar, porém de um modo que sempre desloca e brinca ao "imitar um original de tal forma que a prioridade do original não seja reforçada, porém pelo próprio fato de que o original se presta a ser simulado, copiado, transferido, transformado", isto é, "o 'original' nunca é acabado ou completo em si" (Bhabha, 1990, p. 210). E complementa: 
O 'originário' está sempre aberto à tradução [...] nunca tem um momento anterior totalizado de ser ou de significação - uma essência. O que isso de fato quer dizer é que as culturas são apenas constituídas em relação a aquela alteridade interna a sua atividade de formação de símbolos que as torna estruturas descentradas - é através desse deslocamento ou limiaridade que surge a possibilidade de articular práticas e prioridades culturais diferentes e até mesmo incomensuráveis (Bhabha, 1990, p. 210211).

Aliando os conceitos de representação social, identidade e linguagem - numa acepção onde o contexto é extremamente importante para o dinamismo dos atores/usuários da linguagem - o pesquisador indiano percebe a hibridização para além de processos miméticos que atingem somente uma das partes hibridizadas. $\mathrm{O}$ destaque da visão de Bhabha é que ele vê uma ambivalência na(s) identidade(s) ao apontar um processo dialógico que não separa a construção subjetiva do colonizado da construção da identidade do colonizador. Tal processo hibridizante destaca o papel da alteridade nesta relação (existir é existir para o Outro) como elementos constituintes da identidade híbrida em ambos os sujeito (Souza, 2004, p. 121).

O autor vê a hibridização cultural como algo impossibilitado de ser estanque ou extralinguístico. Para ele o aspecto que torna os processos híbridos dinâmicos é “o reconhecimento do antagonismo" e da heterogeneidade; um antagonismo que não permite o enclausuramento do conceito de cultura. A cultura enquanto "ser híbrido" torna-se uma espécie de "arena antagonística" na qual os conflitos e agências culturais se fazem presente, ressalta Souza (2004). 
Por fim, outro aspecto relevante da conceituação de hibridização em Homi Bhabha é que ele a percebe como um potencial ato político, ético e libertário - em especial, pela força das minorias. Para o autor não importam muito os dois espaços ou momentos originários do híbrido, mas sim, o terceiro espaço que possibilita o surgimento de outras posições e futuros espaços. É este terceiro espaço híbrido que promove e "desloca as histórias que o constituem, e estabelece novas estruturas de autoridade, novas iniciativas políticas" que, "ao serem mal compreendidas através da sabedoria normativa" a desestabilizam e abrem brechas para uma miríade de compreensões da cultura (Bhabha, 1990, p. 211).

A concepção de prática significatória para Bhabha é presente em Guerra (pela sua peculiar representação ideológica, histórica, estética e política) a partir de sua obra artística. O discurso cinematográfico do cineasta é uma prática significatória de seu modo de ver o mundo e de se relacionar com seus pares e situações. Tal prática é também vivenciada em seu discurso acerca do fazer artístico no cinema (Silva, 2013), como é possível ver nas entrevistas dadas pelo diretor.

Suas produções ganham esta significação híbrida por lidar com a visão de um sujeito que não pensa por binômios ou conceitos fixos de cultura, nação, identidade, pátria. A "dubiedade" tão presente nas ideias de Bhabha é também vislumbrada na definição de caráter dos personagens de Guerra (como ocorre com Vavá e Jandi e em "Os Cafajestes") e nas suas narrativas que trilham caminhos nunca óbvios, mas muitas vezes tão metafóricos que se tornam herméticos (como a história por trás da história retratada em "Os Fuzis").

\section{As identidades híbridas, os sujeitos diásporicos e a proliferação subalterna da diferença}


A conceituação de Stuart Hall dada ao hibridismo confunde-se com sua experiência enquanto reflexo de um fluxo migratório de caribenhos para a Inglaterra no século passado. Dito de outro modo, tal reflexo é projetado em suas obras como o retrato daquilo que se convencionou chamar de estudos pós-colonialistas e análises pautadas na diferença, na desterritorialização e no descolecionamento de bases tidas como puras e tradicionais. Hall compreende, assim, a hibridização cultural da seguinte forma:

O hibridismo não se refere a indivíduos híbridos, que podem ser contrastados com os "tradicionais" e "modernos" como sujeitos plenamente formados. Trata-se de um processo de tradução cultural, agonístico uma vez que nunca se completa, mas que permanece em sua indecidibilidade (Hall, 2003, p. 74).

E é justamente durante a tradução cultural que os sujeitos têm diante de si uma cultura que não as assimila, que não as integra e, ao mesmo tempo, não perdem completamente suas identidades originárias: elas ainda guardam, muitas vezes pela forma oral, características que são de seus antigos países. Entretanto, esta tradução exige um confronto: esses sujeitos precisam dialogar inevitavelmente com as duas realidades, com os dois mundos que os tornam híbrido (Hall, 2000, p. 88-89). O destaque da conceituação de hibridização para Hall encontra-se no seu entendimento dos processos hibridizadores como formas potenciais de fontes criativas, isto é, formas criadoras de novas percepções de mundo. O teórico cultural jamaicano afirma isso dizendo que: 
[...] o "hibridismo" e o sincretismo - a fusão entre diferentes tradições culturais - são uma poderosa fonte criativa, produzindo novas formas de cultura, mais apropriadas à modernidade tardia que às velhas e contestadas identidades do passado. (Hall, 2000, p. 91).

$\mathrm{Na}$ esteira dos pensamentos ligados aos sujeitos pós-coloniais, também surge a conceituação de diáspora em Stuart Hall. Entendê-la faz com que a sua visão acerca da hibridização se complemente, pois o pesquisador não dissocia uma questão da outra. Assim, o que o autor entende por diáspora é o deslocamento, normalmente forçado ou incentivado de grandes massas populacionais originárias de uma zona determinada para várias de áreas de acolhimento distintas. Neste sentido, Hall pensa não apenas os motivos destas migrações e seus resultados, mas o entremeio destes processos de mudança.

A partir dessa visão conceitual (e também praxiológica) de Hall é possível entender Ruy Guerra como um sujeito diaspórico e fruto destes deslocamentos territoriais e fronteiriços. Sua vida nômade por vários lugares, desde suas incontáveis mudanças de casa ainda quando criança em Moçambique até os países pelos quais passou já adulto; todos esses deslocamentos são marcantes na vida do diretor. Isso ainda é reforçado por Guerra ser um sujeito pós-colonial, isto é, um indivíduo que soube (tal qual Bhabha e Hall) o que é viver sob o domínio político, social e econômico de um colonizador.

De igual modo, pensar o processo da hibridização para o pesquisador jamaicano é questionar-se sobre aquilo que ele chama de "proliferação subalterna da diferença" (Hall, 2003, p. 60), isto é, a desestabilização da cultura e as perturbações sociais que - 
também vistas na linguagem - são promovidas pelo embate entre moderno e o antigo, entre o que se entende por culto e não-culto, entre classes superiores e inferiores. Dessa forma, mesmo a concepção de hibridização perpassando as implicações da diáspora, Stuart Hall ainda apresenta algo novo: no seio desta discussão estão as zonas de contato que, certamente, representam o desejo desses sujeitos híbridos em retornar ao ponto zero, por um processo consciente ou inconsciente. Mais uma vez: a hibridização em Hall é, sim, uma fonte criativa, mas, simultaneamente, também é uma zona de confronto, uma arena de antagonismos, perturbações e insurgências.

De todos estes apontamentos há pelo menos uma certeza postulada por Stuart Hall: entre estes locais de contato e entre as comunidades e os sujeitos imaginados (termos tomados de Benedict Anderson), a diáspora muda os que saem, muda os que já estão e muda também os que ficaram. Por isso, as conceituações clássicas da geografia já não dão conta de uma leitura plena das sociedades de fronteiras (e transfronteiras): agora, para tentar entendê-las, é preciso localizá-las no devir, nos lugares de passagem (places de passage), quer dizer, nos locais onde os significados também se tornam relacionais, posicionais e nunca definitivos.

Essas mudanças espaciais promovem mudanças também na mundivisão do sujeito diaspórico. Ruy Guerra é um exemplo de como tais mudanças relacionais provocadas pela proliferação subalterna da diferença são projetadas no fazer artístico. É justamente nos lugares de passagem (e não de ancoragem) que a produção audiovisual do cineasta é construída. Guerra demonstra seu olhar movediço em comunhão com sua vida nômade a partir das obras filmadas em Moçambique, Brasil, Espanha, Portugal e outros países (locais não apenas escolhidos pelo simples motivo de realizar filmagens, mas lugares pelos quais o diretor viveu por tempos muito significativos). A cumplicidade entre os lugares de passagem vividos pelo diretor e suas produções são 
uma das formas de representações identitárias híbridas que denotam o presente vivido por ele naqueles dias. Um presente que dizia respeito ao lugar, as emoções e a concepção poética de "eu pertenço ao mundo, a vida e onde estou no momento" tão comentadas por este sujeito diaspórico.

É partindo desta visão de hibridização que Hall coloca, de forma correspondente, que "as identidades, que compunham as paisagens sociais 'lá fora' e que asseguravam nossa conformidade subjetiva com as 'necessidades' objetivas da cultura, estão entrando em colapso" (Hall, 2000, p. 12). E justifica tal colapso como o "resultado de mudanças estruturais e institucionais" pelas quais os processos globalizadores cambiam as sociedades. “O próprio processo de identificação, através do qual nos projetamos em nossas identidades culturais, tornou-se mais provisório, variável e problemático", assegura Hall (2000, p.12).

Para Hall existem três tipos de sujeito iluminista, o sujeito sociológico e o sujeito pós-moderno. O primeiro refere-se ao sujeito centrado, unificado e autossuficiente. O segundo diz respeito ao sujeito que se forma a partir das relações interpessoais mias próximas (uma leitura mais voltada ao interacionismo simbólico). E, finalmente, o terceiro como o sujeito que possui identidades contraditórias e deslocadas: o sujeito da crise de identidade (Hall, 2003). É sobre este sujeito que a visão hibridizadora recai e é tomando-o como ponto de partida que Hall faz suas discussões.

Posto isso, para que o sujeito entenda quem ele é e de que forma o que ele é reflete-se na sua forma de ver, agir e transformar o mundo; primeiramente ele necessita compreender o espaço e o tempo onde vive. O sujeito necessita compreender que sua identidade não é mais fixa, essencial ou permanente como dantes se pensava. “O sujeito assume identidades diferentes em diferentes momentos, identidades que não são 
unificadas ao redor de um 'eu' coerente." (Hall, 2000, p. 13). Ruy Guerra é um ótimo exemplo deste sujeito pós-moderno (Barros, 2009).

Assim, seguindo o pensamento de que a hibridização é potencialmente criativa e ao mesmo tempo conturbada, as desestabilizações da cultura também são potenciais. Pensar nestas desestabilizações é tensionar a suposta neutralidade cultural por parte de um estado liberal, por exemplo, com o pensamento de uma "cultura além das culturas" versus os "particularismos" que se universalizaram de modo hegemônico como "isto é cultura, isto não é cultura". É por isso que Hall aponta a hibridização como o desestabilizador cultural por excelência: o híbrido não aceita conceitos fechados ou oposições binárias. Do mesmo modo, ao não aceitar uma visão de identidade fixa ou dicotômica, Ruy Guerra define-se (mesmo não gostando de definições que o prendam a determinada categoria) como um sujeito, um artista, um amante da arte cinematográfica que pertence à vida e aos seus desejos. Por isso, é sobre sua concepção sui generis de identidade cultural híbrida que o próximo tópico é direcionado.

\section{“O cidadão da vida e seu olhar latino-africano"}

Uma das questões que mais instigou e motivou este trabalho, justamente por não ser de fácil resposta, diz respeito ao olhar autoral de Ruy Guerra e sua relação com um potencial olhar nacionalista, isto é, um olhar a partir de um lugar e de uma pátria. Com mais especificidade, este olhar - mais uma vez, potencial - "tendia", nas reflexões mais superficiais e embrionárias desta pesquisa, a ser um "olhar brasileiro sobre o Brasil". E, mais do que isso: "tendia" a ser um olhar de um brasileiro sobre o mundo representado nas obras de Guerra, ainda que elas fossem filmadas nos países por onde ele passou.

Mas logo apareceram alguns "entraves" a essa ideia. O primeiro deles parece ser o mais óbvio: Como um moçambicano, filho de portugueses, poderia "ser brasileiro" 
tanto quanto seus filmes realizados em "terras brasileiras"? Ou: Como um diretor que viveu em inúmeros outros países com formação francesa cinematográfica e passagens por Cuba, Grécia, Espanha e outras regiões ao redor do globo poderia transparecer justamente esse "olhar brasileiro sobre o Brasil e o mundo"?

Num caminho que parecia dar respostas positivas à tal hipótese inicial, a pesquisadora Luciana Mazzoti afirma que já antes de 1958 (ano de sua chegada ao Brasil), o diretor guardava na memória registros puramente de "natureza brasileira". Principalmente por ouvir marchinhas de carnaval ou pela leitura de José Lins do Rego, Graciliano Ramos, Jorge Amado e Manuel Bandeira, entre tantos outros autores brasileiros. A esta lista, Ruy Guerra completa: “Eu lia Tico-Tico - o Almanaque-, RecoReco, Bolão e Azeitona. Isso chegava lá. Porque havia um público, uma demanda [...] no Maputo, que daquela época era Lourenço Marques". Seu conhecimento do Brasil chegava não só pela revista, mas também pela "música popular e pela poesia..." (Guerra/ TV Câmara, 2009).

Mazotti, ainda sobre a "brasilidade" de Guerra chega a afirmar que, "a despeito da nacionalidade moçambicana e do passaporte português", esse contato com a cultura brasileira e a internalização dela se traduziriam na identificação dele "como cineasta brasileiro". Já que: "[...] é no Brasil que [ele] estabelece os vínculos afetivos mais intensos, principalmente, pelas relações amorosas e pelos filhos" (2006, p. 11).

Tais afirmações, se vistas de modo isolado e sem muitos confrontamentos, pareciam quase que dizer: sim, Guerra, é um "brasileiro", mesmo que tenha a fala de um moçambicano-português e segure a câmera como um francês da Nouvelle Vague. Todavia, "outras falas" começaram a apontar um direcionamento oposto à existência de um "olhar brasileiro" por parte do diretor. 
A primeira delas veio do próprio Ruy Guerra em entrevista ao programa Metrópolis (Guerra/TV Cultura, 2012), comandado por Adriana Couto. Sua resposta, quando indagado sobre "sua definição como um cineasta brasileiro" ou a busca por um adjetivo gentílico, merece a transcrição literal:

Eu já resolvi esse problema há muitos anos. Primeiro: eu anulei o conceito de pátria. Nasci sem pátria: moçambicano era português de segunda classe numa colônia. Oficialmente de segunda classe. Não podia ser presidente da República, não podia ser general, enfim [...]. Então, como eu já tenho mais tempo de vida no Brasil que no resto do mundo, eu me chamo, me auto-nomeei "latinoafricano". Que é uma forma de iludir essa ausência de uma raiz profunda e única. A minha pátria é onde eu vivo, onde eu tenho minhas relações afetivas, tenho minhas relações profissionais. $\mathrm{Na}$ realidade, a minha pátria é onde eu estou.

Outra visão contrária à ideia de um "olhar brasileiro", veio por parte de Eric Nepomuceno. O escritor, na obra "Ruy Guerra - filmar e viver", diz muito sobre isso, ao falar que: "[...] não apenas sua alma é inquieta. Ele a acompanha, deixa-se levar por ela". E conclui definindo-o como um nômade, um habitante de si mesmo. Ruy Guerra é "seu próprio porto" (2006, p. 52).

E é seguindo a mesma linha de raciocínio, que Nepomuceno, agora na série "Sangue Latino", questiona o diretor de uma maneira muito poética: "Ruy, nesses quase 40 anos que a gente se conhece, eu sempre me pergunto: Qual o seu porto? Onde é que você quer chegar?". E recebe como resposta um comentário do diretor sobre suas 
(literalmente) incontáveis mudanças dentro da cidade natal, de como isso parecia ser uma herança, uma marca de seu pai e, logicamente, de que suas próprias andanças pelo mundo tinham uma grande responsabilidade por sua "alma inquieta". Essa dubiedade na definição de uma identidade fixa para Guerra, obviamente, não levaria a lugar algum como mais à frente se percebeu. E um dos maiores motivos da não existência de uma identidade nacional fixa e pronta para o diretor está naquilo que Bhabha chama de processo agonístico da busca por uma identidade híbrida (2010).

Entretanto, é a frase final de Ruy Guerra que realmente mudou o posicionamento inicial desse trabalho acerca do olhar autoral do diretor. Após responder Nepomuceno, já no fim de sua explicação, ele retoma a pergunta inicial e diz: “Agora, porto. Porto? Porto não tem".

E é nessa afirmação metafórica que a questão sobre a existência ou não de uma identidade brasileira desnudou-se: Guerra possui, sim, um olhar nacionalista. Mas nacionalista, como ele mesmo disse, do ponto de vista e da perspectiva de onde ele vive, de onde ele ama, de onde ele trabalha, do lugar no qual ele está em determinados momentos. Ou seja: é um cidadão da vida (Nepomuceno, 2006, p. 52) que possui um olhar nacional não redutivo ao ponto de categorizá-lo como um cineasta moçambicano, ou brasileiro, ou francês, ou português, ou de qualquer nacionalidade.

É justamente esse sentimento de pertença a um local que parece inexistir na concepção de identidade cultural para Ruy Guerra. Hall ainda afirma que pensar a identidade cultural atravessa as relações de poder e as comuns noções de identidade ligada à naturalidade de uma pessoa ao seu local de nascimento. Ao explicar melhor sua conceituação identitária, o pesquisador dos estudos culturais se aproxima muito da definição multiculturalista que Guerra dá a si mesmo: o posicionamento provisório de uma identidade mutante, sempre híbrida (Hall, 2003, p. 433).

Brasiliana - Journal for Brazilian Studies. Vol. 3, n.1 (Jul. 2014). ISSN 2245-4373. 
Por fim, talvez tão importante quanto à "anti-classificação" de Ruy Guerra como um cidadão da vida possuidor de um olhar latino-africano, é aquilo que, de acordo com ele, o faz viver, aquilo que o move e dá sentido ao seu ofício: a utopia. Eric Nepomuceno, tanto no livro quanto na série para televisão, trata desse tema, apresentando Guerra como um "sobrevivente" por manter até hoje uma visão utópica da vida e do mundo, já que para o diretor, é a utopia a única "lei que o interessa". Ruy Guerra, numa resposta contundente explica: “Eu procuro ter o meu horizonte desfocado para ter tempo de ter grandes sonhos. [...] Eu continuo com as mesmas convicções dos meus 18 anos naqueles eixos fundamentais". E finaliza: “[...] Eu continuo achando que as grandes utopias ainda são válidas" (Guerra/Sangue Latino, 2011).

Guerra (2006, p. 21), numa clara alusão a de uma de suas maiores preocupações dentro da perspectiva fílmica, o tempo no cinema, finaliza: "Quando a gente não consegue fechar um conceito dentro da realidade, a gente projeta para o futuro. A utopia no presente deixa de ser presente. Ela precisa ser lançada no tempo". E estas visões, a da utopia e a de um cidadão que, paradoxalmente, mesmo não tendo pátria, sempre a tem, são representadas nas temáticas mais recorrentes e nos usos da linguagem cinematográfica realizadas por Ruy Guerra - um sujeito diaspórico e híbrido. Uma linguagem que, "nas mãos de uns malucos no momento da revolução industrial", iria criar imagens que durariam pra sempre, seriam perenes.

\section{Considerações finais}

Pensar a hibridização a partir do viés identitário é pensar a mistura e a mestiçagem como características intrínsecas aos processos de formação sociocultural. Num ambiente deslocalizado - no qual a ausência de bases fixas e geográficas geram 
fortes características de glocalização, fragmentação, individualidade, liquidez de relações - os processos de hibridização também produzem de modo constante a dúvida e o questionamento acerca da construção híbrida das identidades e dos sujeitos pósmodernos citados por Hall. A comunicação e a cultura (com o cinema como a ponte entre ambas) encontram-se também nessa trama de relações híbridas.

Entretanto, mais do que lidar com as fusões, acomodações, crioulizações, sincretismos, traduções e adaptações híbridas, pensar a hibridização é também pensar em seus resultados, suas consequências e impactos. Em outras palavras, da mesma forma que os elementos primários que co-criam a hibridização são distintos entre si (como exigência per si para que ela ocorra), os elementos derivados de tal mistura já não se caracterizam mais apenas por elencar esta ou aquela característica advinda de seus elementos originários. $\mathrm{O}$ terceiro espaço, como aponta Bhabha, criado pela mistura de dois outros possui aspectos que o tornam singular, híbrido e diferente e não apenas uma "antonomásia" por excelência. Criam o espaço do choque.

Ao invés de entender a hibridização apenas como a possibilidade da mestiçagem, pensar de modo híbrido implica exigências maiores daquele que se propõe a compreendêla. Exige certo desconforto, pouca linearidade e o abandono de conclusões que recaiam em meras relações de causa e efeito. Por isso, pensar tal tema a partir de Ruy Guerra e sua obra audiovisual é um desafio que certamente deixa lacunas por parte do pesquisador que intenta refletir de modo mais profundo acerca do assunto. Lacunas que podem ser preenchidas por leituras e arcabouços culturais mais próprios dos leitores ou por futuras pesquisas.

A importância deste cineasta para a cultura brasileira e para a história do cinema nacional (e, por conseguinte internacional, principalmente, por sua participação no Cinema Novo) é indiscutível. Entretanto, como já colocado no artigo, muitas questões 
acerca de sua identidade e visão de uma "cultura nacional" foram os pontos de partidas que iniciaram esta investigação. A dúvida sobre "Quem é Ruy Guerra?" vista pela identidade cultural foi a grande propulsora.

Assim, ao abordar a vida nômade do cineasta foi possível compreender o quanto sua trajetória é marcada pela mudança territorial de um lugar para outro (seja ainda no país natal Moçambique, seja pelos outros continentes pelos quais passou). Tais mudanças são representadas em suas obras (também filmadas em lugares extremamente distintos um do outro) e denotam o caráter híbrido de sua identidade. Primeiro pela recusa de uma identidade nacional que o fixe a partir de um adjetivo gentílico e, segundo, porque tais experiências diaspóricas estão profundamente arraigadas em seu modo de ver, pensar e fazer cinema - como se não fosse possível separar sua vida nômade de suas películas. Aliás, existe a mínima possibilidade de se separar uma coisa de outra?

Ainda é preciso ressaltar como os estudos pós-colonialistas são importantes para entender esta discussão que trata de autores que viveram as mesmas experiências (em termos de ex-colonizados) que o diretor em questão. As concepções de identidade híbrida para Stuart Hall e Homi Bhabha são tensionadas no artigo de modo que o contexto teórico e prático da fala dos autores parece, a todo tempo, dialogar com o contexto peculiar de leitura da vida nômade de Ruy Guerra.

Em Bhabha, por exemplo, as ideias de processo agonístico a partir da tradução cultural e o discurso como prática significatória são dois dos conceitos trazidos pelo autor que mais se relacionam com o entendimento de Guerra como um sujeito híbrido. Por um sujeito que se vê fora dos padrões de "nacionalidade", mas que, por meio do cinema, produz um discurso que reflete suas dubiedades, ambiguidades e hibridizações próprias. Em Hall as concepções de um sujeito diaspórico que já não se encaixa no país 
de origem e nem se sente totalmente integrado ao país que o recebe também é vista na vida deste cineasta. A ideia de lugares de passagem no percurso traçado por Guerra desde 1962 até os anos mais recentes também demonstra, na práxis, como a discussão trazida pelo pesquisador jamaicano é válida.

Ao se definir como um cidadão da vida possuidor de um olhar latino-africano, Ruy Guerra ratifica a ideia levantada no decorrer de todo o trabalho: sua identidade é multifacetada e híbrida. Seu modo de ver a vida e fazer cinema é um reflexo disso. Um reflexo de uma visão de cultura e identidade que não comporta binarismos, mas que está aberta à mudança, à constante diáspora e ao devir.

\section{Referências}

Aronovich, Ricardo. Ruy Guerra e Eu. In: PAPA, Dolores (org.). Ruy Guerra: filmar é viver. S. Paulo: Centro Cultural Banco do Brasil, 2006.

Barros, Eduardo Portanova. O cinema de Ruy Guerra: um imaginário autoral na pósmodernidade. 2009. Tese (Doutorado em Comunicação Social) - Universidade Federal do Rio Grande do Sul.

Bhaba, H. Representation and the Colonial Text: a critical exploration of some forms of mimeticism. In: Gloversmith, F. (ed.). The theory of reading. Brigthon: Harvester, 1984, p. 93-122.

. The Third Space. In: Rutherford, J. (ed.). Identity: community, culture, difference, London: Lawrence \& Wishart Rutherford, 1990, p 207-215.

. O local da cultura. Belo Horizonte: Autêntica, 2010.

García Canclini, N. Culturas híbridas: estratégias para entrar e sair da modernidade. (Trad. Heloísa P. Cintrão e Ana Regina Lessa). 4. ed. São Paulo: Edusp, 2011.

Gomes, Paulo E. S. Cinema: trajetória no subdesenvolvimento. São Paulo: Paz e Terra, 1996.

Brasiliana - Journal for Brazilian Studies. Vol. 3, n.1 (Jul. 2014). ISSN 2245-4373. 
Graça, Marcos da Silva. A herança maldita do Cinema Novo. In: Graça; Marcos da S.; Amaral, Sergio B.; Goulart, Sonia. Cinema brasileiro: três olhares. Rio de Janeiro: EDUFF, 1997.

Guerra, Ruy. Entrevista: trabalhar com o oculto e o que já se esqueceu. In: Papa, Dolores (org.). Ruy Guerra: filmar é viver. S. Paulo: Centro Cultural Banco do Brasil, 2006.

. In: Sintonia, Brasília: TV Câmara, 2009 (programa de TV). 24 de novembro de 2009 (programa de TV).

. In: Sangue Latino, Rio de Janeiro: TV Brasil/ TV Cultura/ Urca Filmes, 8 de agosto de 2011 (Programa de TV).

. In: Metrópolis, São Paulo: TV Cultura, 13 de setembro de 2012 (programa de TV).

Hall, S. A identidade cultural na pós-modernidade. 3. ed. Rio de Janeiro: DP\&A, 2000. . Da diáspora: identidades e mediações culturais. São Paulo: Humanitas, 2003.

Mazzoti, Luciana. Ruy Guerra: uma biografia, entre outras. In: Papa, Dolores (org.). Ruy Guerra: filmar é viver. S. Paulo: Centro Cultural Banco do Brasil, 2006.

Nepomuceno, Eric. Sobre um amigo radical e bissexto. In: Papa, Dolores (org.). Ruy Guerra: filmar é viver. S. Paulo: Centro Cultural Banco do Brasil, 2006.

Paranaguá. Paulo A. Ruy Guerra. In: Ramos, Fernão; Miranda, Luiz Felipe (org.). Enciclopédia do Cinema Brasileiro. 2. ed. São Paulo: Senac, 1997.

Rocha, Glauber. Ruy Guerra 80. In: Papa, Dolores (org.). Ruy Guerra: filmar é viver. S. Paulo: Centro Cultural Banco do Brasil, 2006.

Saraceni, Paulo César. Por dentro do cinema novo - Minha viagem. Rio de Janeiro: Nova Fronteira, 1993. 
Silva, Anderson Lopes da. O cinema autoral em Ruy Guerra: uma análise fílmica de "Os cafajestes" (1962). 2013. Monografia (Especialização em Comunicação, Cultura e Arte) Pontifícia Universidade Católica do Paraná, Curitiba-PR, Brasil.

Souza, L. M. T. M. Hibridismo e tradução cultural em Bhabha. In: Abdala Júnior, B. (org). Margens da cultura: mestiçagem, hibridismo \& outras misturas. São Paulo: Boitempo Editorial, 2004. 